\title{
DUKUNGAN LANSKAP CANDI NGAWEN TERHADAP KONSERVASI KAWASAN CAGAR BUDAYA NASIONAL BOROBUDUR
}

\author{
Aprilia Widiasari \\ aprilia_widiasari@yahoo.co.id
}

\begin{abstract}
ABSTRAK
Candi Ngawen merupakan salah satu candi dengan latar belakang agama Buddha yang berada di Kabupaten Magelang, Jawa Tengah. Lokasinya cukup dekat dengan tiga candi Buddha lainnya yaitu Candi Mendut, Candi Pawon dan Candi Borobudur yang sudah ditetapkan UNESCO menjadi Warisan Dunia. Candi Ngawen memiliki keunikan tersendiri yang tampak dari denah tata letak, arca dan relief yang sangat ikonik. Selain itu, Candi Ngawen berada di lingkungan yang memiliki potensi ekonomi, sosial, budaya serta alam yang sangat menarik. Upaya-upaya pelestarian pun telah banyak dilakukan. Tulisan ini membahas tentang gambaran kondisi lanskap Candi Ngawen yang masih relatif terjaga, sehingga mampu memberikan dukungan terhadap konservasi Kawasan Cagar Budaya Nasional Borobudur. Teknik pengumpulan data dilakukan dengan studi pustaka, kemudian analisis dilakukan secara induktif.
\end{abstract}

Kata Kunci: lanskap, konservasi, kawasan, cagar budaya

\section{ABSTRACT}

Ngawen Temple is one of Buddhis Temples which is located in Magelang Regency, Central Java Province. Its Location is very close to others three Buddhis Temples, Mendut, Pawon, dan Borobudur Temples. The three temples are already listed as a world heritage site. Ngawen Temple has very unique characteristics regarding the ground plan, statues and its iconic reliefs. Ngawen Temple also situated in the area which has economic, social, culture and nature potentials. Conservation measures have been conducted in this area concerning the nature landscape. This paper is aimed to discuss Ngawen Temple landscape condition which still well preserved so that it can support the conservation of Borobudur National Heritage Compound. Data is gathered by survey and literature study. The next step is data analysis which is conducted inductively.

Keywords: Landscape, Conservation, Compound, Culture Heritage 


\section{PENDAHULUAN}

Sebelum datangnya agama Hindu dan Buddha masuk ke Indonesia, masyarakat lokal Indonesia telah menganut sistem kepercayaan animisme dan dinamisme, yaitu kepercayaan yang mempercayai ruh nenek moyang, pohon-pohon besar, atau binatang sebagai dewa. Ketika agama Hindu-Buddha masuk ke Indonesia terjadi perubahanperubahan di dalam masyarakat, seperti upacara-upacara keagamaan, tata krama, serta bentuk peribadatan.

Wilayah Jawa Tengah memiliki banyak tinggalan arkeologis mulai dari masa Prasejarah, Klasik Hindu-Buddha, Islam hingga Kolonial. Tinggalan arkeologis tersebut berupa benda, bangunan, struktur, situs maupun kawasan baik yang masih diduga maupun yang sudah ditetapkan sebagai cagar budaya.

Kabupaten Magelang merupakan salah satu wilayah administrasi di Propinsi Jawa Tengah yang memiliki banyak tinggalan Cagar Budaya masa Klasik Hindu-Buddha. Tinggalan tersebut berupa benda, bangunan, struktur, situs maupun kawasan yang didalamnya berupa candi baik yang masih utuh maupun yang sudah tidak utuh lagi. Kabupaten Magelang memiliki banyak tinggalan Cagar Budaya berupa candi yang tersebar di lereng-lereng Gunung Merapi, perbukitan, dataran bahkan di dekat aliran sungai. Salah satu tinggalan Cagar Budaya tersebut adalah Candi Ngawen. Candi Ngawen merupakan candi dengan latar belakang agama Buddha yang terletak di Desa Ngawen, Kalurahan Ngawen, Kecamatan Muntilan, Kabupaten Magelang.

Secara administrasi, Candi Ngawen berada di Desa Ngawen, Kalurahan Ngawen, Kecamatan Muntilan, Kabupaten Magelang. Secara astronimis berada pada posisi

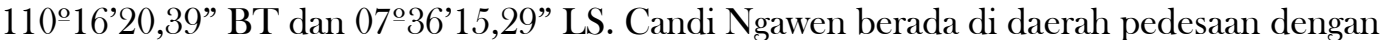
kondisi lingkungan alam yang masih asri dan secara demografi berada pada penduduk yang bermatapencaharian sebagai petani (Junawan,dkk: 2012: 5).

Candi Ngawen merupakan candi dengan latar belakang agama Buddha, hal ini berkaitan dengan ditemukannya dua Arca Dhyani Budha Ratnasambhava yang saat ini diletakkan di Candi II dan Arca Dhyani Budha Amitabha diletakkan di Candi IV. Terkait dengan masa pembangunannya, ada banyak pendapat yang dikemukakan, karena sampai saat ini tidak ditemukan angka tahun ataupun bukti tertulis lainnya yang berkaitan dengan pendirian Candi Ngawen.

Dilihat dari denah tata letaknya, Candi Ngawen ini cukup unik karena merupakan suatu kompleks percandian yang terdiri dari lima buah candi yang disusun secara berjajar dari Utara ke Selatan, dengan arah hadap ke Timur. P. J. Perquin dan Bernet Kempers (dalam Harjono, 1980:1-2) mengurutkan candi-candi tersebut dari utara ke selatan dengan sebutan Candi Ngawen I, Candi Ngawen II, Candi Ngawen III, Candi Ngawen IV dan Candi Ngawen V, dan secara arsitektur Candi Ngawen terbagi dalam dua kelompok, yaitu kelompok Candi Ngawen I, II, IV dan kelompok Candi Ngawen II dan V. Pengelompokan ini berdasarkan pada kesamaan ukuran dan bentuk denah bangunan, dan untuk saat ini Candi Ngawen II yang memiliki bentuk relatif utuh hingga pada bagian atap tingkat 1. Selain tata letak dan arsitekturnya yang berbeda dengan candi Buddha pada umumnya, yang menarik perhatian pada Candi Ngawen adalah adanya arca Singa Jantan. Keberadaan arca singa tersebut memberikan keunikan tersendiri, keunikan terlihat dari bentuk dan penempatan arca singa di keempat sudut Candi Ngawen (Harjono, 1980:1-2).

Keberadaan Candi Ngawen telah menarik perhatian sejak jaman Pemerintahan Hindia Belanda. Dalam beberapa catatan Belanda, antara lain: Oudheidkundige Dienst in Nederlandsch-Indie Oudheidkundige Verslag 1916, 1921, 1929, Rapporten Oudheidkundigen Dienst Java en Madoera 1911, dan Rapporten van den Oudheidkundigen Dienst in Nederlandsch-Indie 1914: Inventaris der Hindoe-Oudheden menyebutkan bahwa Candi Ngawen ditemukan di area persawahan dalam kondisi terkubur dan tidak utuh. Bagian-bagian candi banyak ditemukan baik berupa fragmen maupun arca. 
Dalam laporan ini juga menyebutkan langkah-langkah pelestarian seperti penggalian, pencatatan, penggambaran dan pendokumentasian. Pada tahun 1841, Hoepermand menemukan Candi Ngawen dalam kondisi yang sudah tidak utuh lagi, perlakuan Hoepermand terhadap temuan tersebut yaitu dengan melalukan pencatatan. Pada tahun 1911, Van Erp melakukan penelitian dan menyebutkan bahwa Candi Ngawen hancur akibat letusan Gunung Merapi. Pada sekitar tahun 1925 - 1927, seorang P. J. Perquin berhasil memugar Candi I dan II.

Upaya-upaya pelestarian perlu dilakukan terhadap Cagar Budaya dan lanskapnya. Menurut beberapa pendapat tentang pelestarian atau konservasi dari beberapa peneliti diantaranya menurut Rahardjo (dalam Hartatik, 2014: 99); Sharer (dalam Dananjaya, 2012: 14); Orbasli (2008: 38); Tanudirdjo (tanpa tahun: 5); Tanudirdjo (tanpa tahun: 2) dapat ditarik sebuah pengertian bahwa pelestarian merupakan bentuk pelindungan, pengembangan dan pemanfaatan terhadap Cagar Budaya dengan tetap mempertahankan makna budayanya dilakukan secara berkelanjutan agar dapat diwariskan dengan tujuan untuk kepentingan masyarakat.

\section{PERMASALAHAN}

Candi Ngawen merupakan budaya materi hasil dari interaksi antara manusia dengan lanskap. Sejak saat ditemukan pada tahun 1874 oleh Hoepermans, kondisi Candi Ngawen sudah tidak utuh lagi, saat ini yang sudah berhasil dipugar adalah Candi Ngawen II, namun bagian atapnya tidak sempurna karena komponen penyusunnya tidak ditemukan. Pada saat ini lanskap budaya Candi Ngawen juga sudah mengalami perubahan, dengan tumbuhnya pemukiman penduduk atau perubahan fungsi lahan. Kondisi tersebut menurut Ahimsa-Putra (2007: 17) pelestarian cagar budaya tidak hanya pada bendanya saja, akan tetapi juga pada lingkungan sekitarnya, hal ini disebabkan adanya hubungan yang tidak terputus antara cagar budaya dengan lingkungannya sejak jaman dulu hingga saat ini. Sejak kurun waktu tersebut kondisi lingkungan sekitar dapat mengalami perubahan. Perubahan kondisi lingkungan ini mempengaruhi upaya pelestarian cagar budaya. Berdasarkan kondisi tersebut, maka permasalahan yang ingin diangkat adalah bagaimana komponen lanskap Candi Ngawen memberikan dukungan dalam konservasi Kawasan Cagar Budaya Nasional Borobudur?

\section{METODE}

Penelitian ini dilakukan di Desa Ngawen, Kalurahan Ngawen, Kecamatan Muntilan, Kabupaten Magelang tempat Situs Candi Ngawen berada. Penelitian ini merupakan penelitian kualitatif deskriptif dengan teknik pengumpulan data dengan survey dan studi pustaka. Data yang dikumpulkan adalah yang terkait dengan kondisi lingkungan sekitar Candi Ngawen. setelah data terkumpul selanjutnya dilakukan analisis secara induktif.

\section{DISKUSI DAN PEMBAHASAN \\ Lanskap Candi Ngawen}

Plachter dan Rossler (dalam Rahmi, 2012: 3) lanskap sebagai hubungan antara kondisi alam dan budaya manusia dalam suatu ruang dan waktu yang lama dalam bentuk fisik dan nonfisik. Muhammad (2009: 1-5) lanskap merupakan perpaduan antara komponen fisik bumi, makhluk hidup dan karya manusia dalam suatu ruang hunian. Rahmi (2012: 86) lanskap merupakan produk kreativitas manusia dalam mengubah bentang lahan (landscape) dalam waktu yang lama sehingga didapatkan keseimbangan harmoni kehidupan antara alam dan manusia. 
Menurut Knapp dan Ashmore (1999: 1) lanskap dilihat sebagai kesatuan yang ada berdasarkan yang dirasakan, dialami, dan dikontekstualisasikan oleh manusia. Harrison (2004: 13) lanskap adalah alat konseptual yang penting dalam analisis hubungan antara manusia dan tempat (Brown, 2007: 34). Menurut Yuwono (2007: 116) terdapat beberapa istilah yang hampir sama dengan istilah lanskap, yaitu bentanglahan, fisiografi dan lingkungan. Lanskap adalah suatu wilayah di permukaan bumi dengan delineasi (batasbatas) tertentu yang ditunjukkan melalui suatu geotop atau kelompok geotop (yaitu bagian geosfera yang relatif homogen dari segi bentuk dan prosesnya). Sementara itu, lanskap menurut Simon dan Starke (2006) (dalam Aryanto, 2012: 976) adalah bentang alam dengan sistem yang kompleks dalam bentuk interaksi komponen biotik dan abiotik dan dapat dirasakan oleh pancaindra manusia (Aryanto, 2012: 976).

Ruang dan waktu mempengaruhi lanskap, sehingga lanskap memiliki ciri-ciri atau karakter tertentu dan memiliki sifatnya masing-masing. Dengan memiliki karakter tertentu, lanskap dapat dibedakan dalam beberapa jenis, antara lain: natural landscape biasa disebut pemandangan atau penampakan permukaan bumi, physical landscape terdiri dari komponen alam dan kenampakan budaya, social landscape bentanglahan yang menggambarkan kehidupan sosial-ekonomi penduduk, economical landscape bentanglahan yang beragam yang berorientasi ekonomis, dan cultural landscape merupakan bangunan/unsur budaya dengan natural features sebagai latar belakangnya (Yuwono, 2007:117-118).

Pada tahun 1925, Carl Sauer (dalam Brown, 2007: 34) memperkenalkan istilah lanskap budaya dalam sebuah esai tentang Morfologi Lanskap, menurutnya lanskap budaya memberi ekspresi pada cara hidup di suatu tempat. Dia menyatakan, Lanskap budaya dibuat dari pemandangan alam oleh kelompok budaya. Budaya adalah agen, area alam adalah sarana/medium, lanskap budaya adalah hasilnya (Brown, 2007: 34).

Lanskap sudah dijelaskan dengan beberapa definisi di atas. Sementara budaya berasal dari bahasa Sansekerta dari kata buddhi yang berarti akal, bahasa Latin berasal dari kata colere yang berarti mengerjakan atau mengolah. Budaya menurut bahasa Indonesia (KBBI) merupakan pikiran, akal budi, adat istiadat, sesuatu mengenai kebudayaan yang sudah berkembang, sesuatu yang sudah menjadi kebiasaan yang sudah sukar diubah. Budaya memiliki beberapa unsur-unsur yang bersifat universal. Dianggap universal karena unsur-unsur tersebut dapat ditemukan pada kebudayaan manusia di dunia.

Berdasarkan beberapa definisi dan karakter tersebut, maka keberadaan Candi Ngawen dan lingkungannya masuk di dalam jenis cultural landscape atau lanskap budaya, karena memnuhi unsur-unsur, antara lain: Candi Ngawen sebagai unsur budaya dalam sistem religi dan teknologi yang berada atau didirikan pada bentanglahan tertentu. Lanskap terbentuk oleh sistem alam dan dibentuk oleh sejarah dan budaya. Istilah lanskap budaya sering digunakan dalam bidang geografi manusia, antropologi dan arkeologi (Brown, 2007: $34)$.

Candi dibangun dengan modifikasi yang disesuaikan dengan kondisi setempat, seperti pada bentuk, ornamen dan bahan. Karena dalam pembangunan sebuah candi sebagai tempat sakral juga perlu memperhatikan secara teknis dan ideologi keagamaan. Penyesuaian atau modifikasi tersebut tidak hanya karena faktor keagamaan dan teknis, akan tetapi juga menyesuaikan dengan kondisi lingkungan alamnya. Menurut ketentuan yang ada dalam wastupurusamandala seperti yang disampaikan oleh Soekmono (1974: 330), lahan untuk mendirikan suatu bangunan suci dinilai amat tinggi, bahkan lebih berharga daripada bangunan suci itu sendiri.

Candi merupakan salah satu hasil karya seni bangunan yang penting di Indonesia, sebagai suatu bukti jejak perkembangan kebudayaan manusia. Tujuan didirikannya candi adalah untuk pemujaan terhadap dewa-dewa, sehingga dalam pembuatannya harus 
memenuhi aturan-aturan yang ada dalam kitab Vastusastra. Ada beberapa kitab Vastusastra, antara lain Manasara, Silpaprakasa, Visnudharmottaram. Aturan pendirian candi juga termuat dalam kitab Purana dan Agama (Hardiati, 1998: 3).

Menurut Firdani (t.t: 3) secara geografis Kabupaten Magelang dibagi menjadi 3 bagian, yaitu bagian tengah yang terletak di antara Sungai Progo dan Sungai Elo berupa dataran rendah dan lembah; bagian barat terletak di Lereng Gunung Sumbing dan Pegunungan Menoreh, sedangkan bagian di sebelah timur berupa Pegunungan terletak di lereng Gunung Merapi, Gunung Merbabu, Gunung Telomoyo dan Gunung Andong; dan di bagian utara berupa dataran tinggi. Berdasarkan gambaran geografis tersebut, wilayah Kabupaten Magelang memiliki topografi dataran tinggi yang memiliki cekungan. Daerah cekungan seperti ini menjadi daerah tangkapan air, yang memiliki nilai positif terhadap kesuburan tanah, selain itu juga adanya abu vulkanik sisa letusan yang terendap di dalam tanah.

Pada saat ini Candi Ngawen berada di dataran rendah, menempati tanah yang datar berjarak \pm 500 meter ke arah barat dari Sungai Blongkeng, selain Sungai Blongkeng juga ada Sungai Kebo. berdasarkan hasil pengamatan penulis, kedua sungai tersebut memiliki debit air yang berbeda. Sungai Blongkeng debit sungainya lebih besar, selain dimanfaatkan untuk keperluan irigasi dan kebutuhan sehari-hari rumah tangga, juga digunakan untuk wisata air berupa river tubbing. Pemandangan Gunung Merapi dapat terlihat dengan jelas, Bukit Menoreh dan Bukit Gunung Sari. Lingkungan sekitar kompleks candi berupa lahan persawahan yang subur. Pada sisi Utara candi sudah banyak pemukiman penduduk.

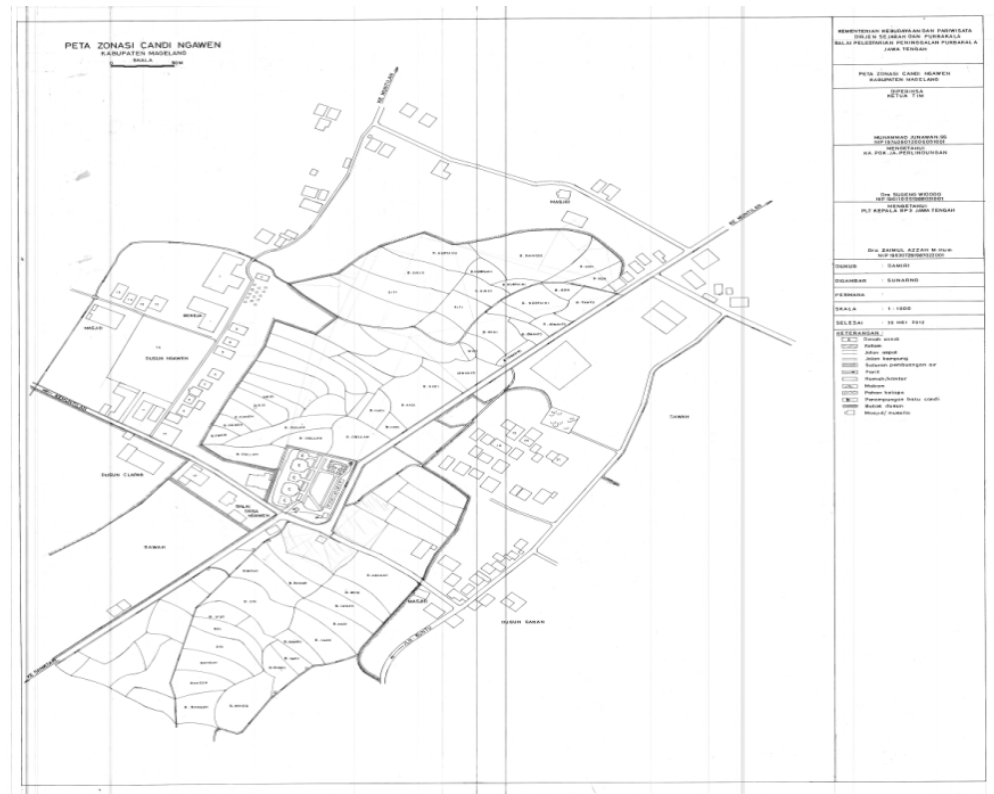

Foto 1: Peta Situasi Candi Ngawen Tahun 2012

(Sumber: Balai Pelestarian Cagar Budaya Jawa Tengah)

Menurut Acharya (1981) yang dikutip oleh Ambarwati (2009: 4), yang diatur dalam Vastusastra tentang pendirian bangunan, antara lain: (1) pemilihan lokasi site, (2) bentuk dasar bangunan, (3) arah hadap bangunan (4) titik pusat suci (sanctum), (5) bentuk Meru pada atap, dan (6) susunan ruang (Ambarwati, 2009: 4). Dalam proses pembangunan suatu candi bahwa pendeta dan arsitek harus menilai kondisi dan kemampuan lahan dan menentukan teknik pembangunannya. Lebih lanjut menurut Kramrisch (1949) yang dikutip oleh Istari (2012: 29) menyebutkan bahwa dalam pemilihan lahan perlu mempertimbangkan jenis tanahnya dan lingkungan sekitarnya yang berdekatan dengan 
sumber air, seperti dananu, sungai, mata air, muara sungai dan laut (Istari, 2012:29). Dalam kitab Manasara juga menyebutkan bahwa bangunan suci sebaiknya didirikan di dekat tempat-tempat yang digunakan dewa untuk "bercengkrama", yaitu yang disebut _tirtha (air). Tirtha adalah tempat yang mengandung air, seperti danau, sungai, mata air, muara sungai dan laut. Pertimbangan memilih lokasi yang dekat dengan sumber air, karena air mempunyai kemampuan membersihkan, mensucikan dan juga menyuburkan. Tetapi candi juga dapat didirikan di puncak bukit, lereng gunung, hutan, lembah (Hardiati, 1998: 3).

Dalam kitab Silpaprakasa ada kategori lahan yang baik dan yang tidak baik untuk mendirikan bangunan suci. Adapun lahan yang baik untuk mendirikan bangunan suci adalah yang banyak mengandung pasir, sementara yang tidak baik adalah lahan yang tidak ada sungai atau sumber air lainnya, lahan yang berkerikil, lahan berupa rawa, dan tempat untuk membakar mayat (Boner dan Sarma, 1966: 10).

Berdasarkan hasil tinjauan Geologi di lingkungan sekitar Candi Ngawen, ditemukan banyak mata air maupun rembesan air tanah di sekitar Candi Ngawen. Hal tersebut akibat dari timbunan letusan Gunung Merapi yang mempengaruhi tatanan batuan di sekitar Candi Ngawen. Air tanah ini mengandung fero (fe) dan berwarna kuning, dapat dilihat pada sumur-sumur warna dan parit yang berada dekat dengan Candi Ngawen (Junawan, dkk: 2012: 13).

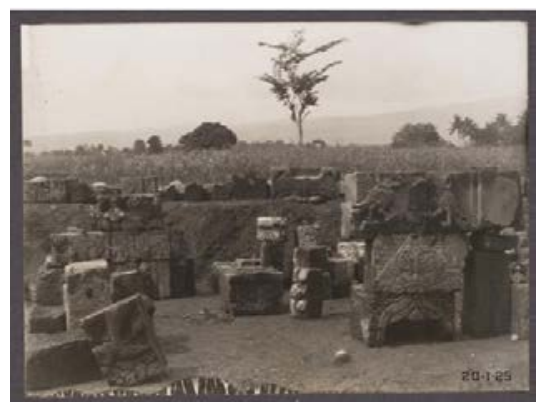

Foto 2: foto reproduksi tahun 1925

(Sumber: http://digitalcollection.universiteitleiden.nl)

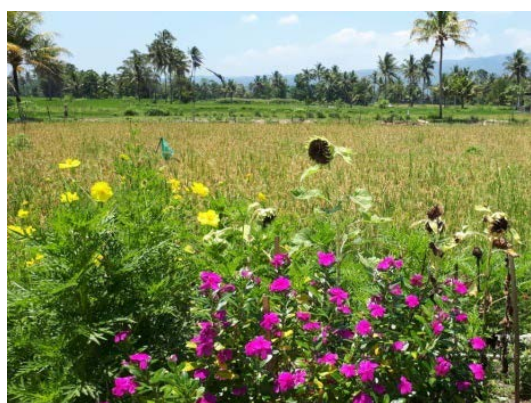

Foto 3: situasi lingkungan sekitar Candi Ngawen tahun 2018 (Sumber: koleksi pribadi)

Selain dibangun di daerah yang dekat dengan air, Candi Ngawen juga berada dekat dengan areal persawahan. Persawahan ada karena untuk menopang kehidupan masyarakat pendukung candi. Seperti yang disampaikan oleh Clifford Geertz, bahwa di Jawa sistem pertanian sawah dengann pengairan merupakan sistem pertanian yang berkesinambungan tanpa putus. Teknik seperti ini sudah lama dilakukan oleh penduduk Jawa. Sistem pertanian sawah irigasi telah muncul untuk pertama kalinya di lembah sungai Progo dan sungai Elo, disebuah dataran alluvial yang dikelilingi gunung berapi seperti gunung Sindoro, gunung Sumbing, gunung Merapi dan gunung Merbabu (Tim, 2012: 3 - 4). 

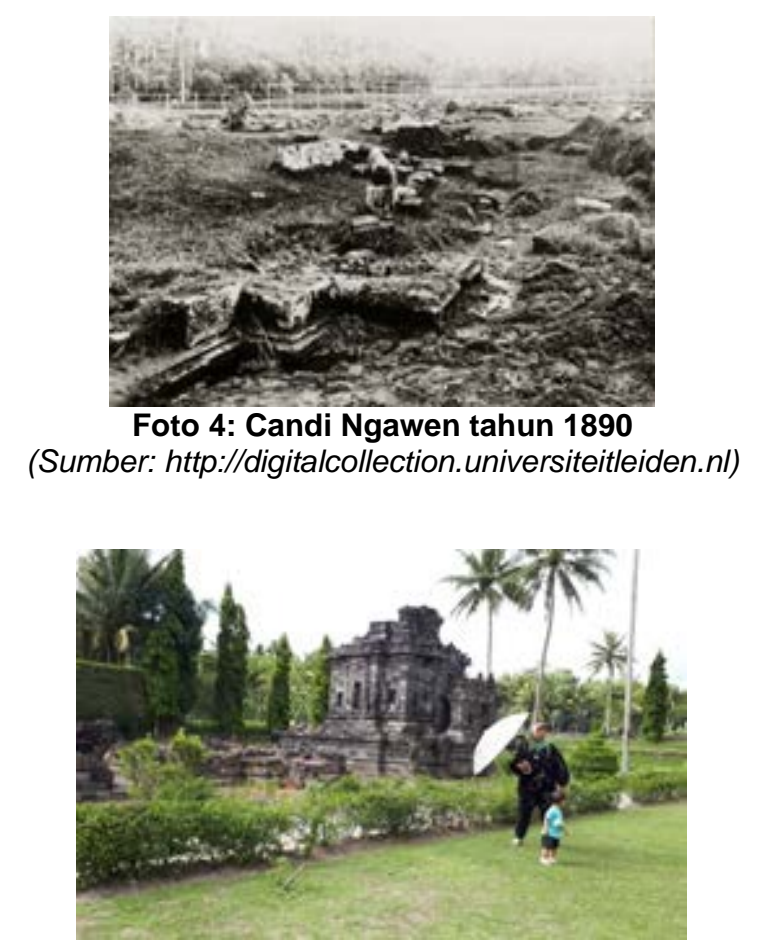

Foto 5: Candi Ngawen tahun 2018

(Sumber: koleksi pribadi)

Di Jawa Tengah terdapat dua kelompok percandian, yaitu kelompok dataran Prambanan dan kelompok lemah Progo. Menurut Degroot (2009: 47), daerah lembah Progo merupakan daerah yang tidak terbuka karena terhalang oleh barisan bukit dan gunung, seperti gunung Sindoro, gunung Sumbing, gunung Merapi, gunung Merbabu dan bukit Menoreh. Lembah Progo merupakan tempat yang memiliki kepadatan tinggalan candi nomor dua setelah dataran Prambanan. Selain itu, merupakan tempat yang makmur, relatif padat penduduknya, dan layak menjadi pusat kehidupan. Candi Ngawen merupakan salah satu candi yang menempati daerah lembah Progo.

Pemilihan lembah Progo untuk mendirikan tempat yang dianggap suci menunjukkan bahwa lokasi tersebut memiliki arti penting bagi masyarakat pendukungnya. Menurut Soekmono (1974: 329 - 330) pola penempatan situs atau candi dapat menunjukkan pola pikir atau gagasan masyarakatnya. Pemilihan ini dengan syarat harus dekat dengan sumber air, karena air digunakan dalam ritual keagamaan dan sebagai media untuk mensucikan. Selain itu, juga kadar kegaiban suatu tempat juga menjadi pertimbangan. Menurut Mundarjito (2002: 283-286), lokasi untuk mendirikan bangunan suci seperti candi biasanya berada di lahan tidak terlalu tinggi, landai, berupa dataran fluvio, dekat dengan aliran sungai dan yang terpenting adalah daerahnya subur. Dengan lahan yang tidak terlalu tinggi memberikan kemudahan bagi manusia untuk melakukan aktivitas seharihari. Selain itu, pada dasar-dasar sungai yang dilalui oleh material vulkanik banyak ditemukan batu-batu dalam ukuran besar yang dapat dimanfaatkan sebagai sumber pembangunan candi.

Menurut Setyawati (2016: 9), secara geologi kawasan Kabupaten Magelang berupa endapan Gunung Api Merapi Muda yang terdiri dari Tuf, Abu, Breksi, Aglomerat dan leleran lava yang tak terpisahkan, juga berupa aluvium yang terdiri dari kerakal, pasir dan lanau serta endapan Gunung Api Merapi Tua yang terdiri dari Breksi, Aglomerat dan leleran lava yang tak terpisahkan, Andesit dan Basal yang mengandung Olivin. 
Desa Ngawen merupakan salah satu wilayah di Kabupaten Magelang dengan kondisi tanah Alluvial dan Regosol dari endapan merapi muda . Jenis tanah ini merupakan endapan dari material erupsi gunung berapi yang mengandung Abu Vulkanik, mineral dan unsur hara yang tinggi, maka tanah jenis ini sangat subur dan cocok untuk pertanian. Menurut Acharya dan Kramrisch (dalam Mundardjito, 2002: 11) menyatakan bahwa kondisi tanah yang subur merupakan syarat terpenting dalam menentukan suatu tempat untuk dijadikan tempat mendirikan candi. Syarat tersebut terdapat dalam kitab ManasaraSilpasastra. Menguji kesuburan tanah dilakukan sebelum dijadikan tempat untuk mendirikan candi, kemampuan tanah juga diuji untuk mengetahui tentang daya serapnya dan derajat kemelesakannya.

Kondisi tanah yang subur selain berkaitan dengan pendirian candi, cocok juga untuk dijadikan lahan pertanian. Menurut Profil Desa Ngawen tahun 2017 menyebutkan bahwa Desa Ngawen memiliki lahan pertanian seluas 138,94 Ha, luas lahan pertanian lebih luas daripada lahan pemukimannya yang hanya 48,36 Ha. Berdasarkan data tersebut, pertanian menjadi potensi utama sumberdaya alam yang dimiliki Desa Ngawen. Menurut Boechari dan Jones (dalam Mundardjito, 2002: 282) dari hasil kajiannya terhadap beberapa prasasti Jawa Kuna menyebutkan bahwa pada masa lalu hasil pertanian merupakan salah satu komponen utama pendukung kehidupan candi baik untuk penyelenggaraan upacara maupun untuk pemeliharaan sehari-hari.

\section{Candi Ngawen Bagian Dari Kawasan Cagar Budaya Nasional}

Kondisi lanskap Candi Ngawen hingga saat ini relatif masih terjaga, kawasan Ngawen identik dengan persawahan dan gunung, meskipun telah banyak pemukiman penduduk disekitarnya. Sehingga, kedudukannya pun patut dipertimbangkan sebagai suatu kawasan yang mempu mendukung konservasi Kawasan Cagar Budaya.

Di dalam tindakan konservasi, terkadang ada istilah restorasi dan rekonstruksi. Menurut Venice Charter (1964) istilah restorasi mengacu pada tindakan mengembalikan sesuatu ke keadaan semula atau asli, tetapi tanpa menambahkan materi baru dan tidak harus bertujuan untuk kesatuan dalam gaya. Sedangkan menurut konservasi saat ini, konservasi bertujuan untuk melestarikan dan mengungkapkan nilai-nilai historis dan estetika, berdasarkan pada bahan asli Terlepas dari apakah rekonstruksi, restorasi atau konservasi yang diperdebatkan dan pendekatan yang berbeda semuanya bertujuan sama, yaitu untuk mempertahankan keaslian dan perasaan orisinalitas, mengusahakan segala sesuatunya sedekat mungkin dengan aslinya dan selama mungkin dapat dipertahankan. Selain itu, tahap akhir dalam proses restorasi dan konservasi adalah sesuatu yang lengkap.

Menurut Karlstrom (2013: 141) bahwa makna konservasi yaitu konservasi tidak selalu terkait dengan keabadian, melainkan untuk berubah, dan pentingnya keterlibatan kelompok lokal dalam pengelolaan warisan. Di dalam pelestarian terdapat aspek integritas (condition of integrity) yaitu ukuran dari keutuhan dan kesatuan objek dengan atributatributnya. Menurut Jokilehto (2006: 13 - 14) didalam pelestarian perlu memperhatikan kesatuan struktural terhadap lokasi atau tempat dimana objek atau bangunan tersebut berdiri/dibangun dan terdokumentasi dengan lengkap dan detail. Stovel (2007: 24 - 25) menjelaskan salah satu aspek integritas yaitu kesatuan (intactness) akan berkaitan erat dengan atribut lingkungan yang berpotensi mengancam terhadap eksistensi objek atau bangunan, sehingga elemen kesatuan atau intactness dalam perspektif lingkungan fisiknya harus diterjemahkan sebagai suatu kondisi kesatuan objek atau bangunan dengan lingkungan fisik sekitarnya yang terjamin tidak mengancam atau membahayakan dari aspek pelestarian. 
Dalam Burra Charter Article No. 2 tentang Conservation and Management pada point 2.4 menyebutkan "places of cultural significance should be safeguarded and not put a risk or left in vulnerable state". Kemudian dipertegas pada Article No. 9 dan 10 tentang Location:

"9.1 The physical location of a place is part of its cultural significance. A building, work or other element of a place should remain in its historical location. Relocation is generally unacceptable unless this is the sole practical means of ensuring its survival".

"9.2 Some buildings, works or other elements of places were designed to be readily removable or already have a history of relocation. Provided such buildings, works or other elements do not have significant links with their present location, removal may be appropriate".

"9.3 If any building, work or other element is moved, it should be moved to an appropriate location and given an appropriate use. Such action should not be to the detriment of any place of cultural significance".

Article No. 10 menyebutkan tentang Content:

"Contents, fixtures and objects which contribute to the cultural significance of a place should be retained at that place. Their removal is unacceptable unless it is: the sole means of ensuring their security and preservation; on a temporary basis for treatment or exhibition; for cultural reasons; for health and safety; or to protect the place. Such contents, fixtures and objects should be returned where circumstances permit and it is culturally appropriate."

Kaitan antara Candi Ngawen dengan Candi Borobudur, Candi Mendut dan Candi Pawon yang telah menjadi Warisan Dunia adalah Candi Ngawen salah satu situs yang termasuk dalam satu kawasan cagar budaya borobudur. Dan sebagai syarat menjadi Warisan Dunia adalah dengan memiliki status cagar budaya peringkat nasional, sehingga ditetapkan dengan Keputusan Menteri Pendidikan dan Kebudayaan Nomor 286/M/2014 tentang Satuan Ruang Geografis Borobudur sebagai Kawasan Cagar Budaya Peringkat Nasional (Ardiyansyah, 2019: 57). Menurut Undang-Undang No. 11 Tahun 2010 tentang Cagar Budaya pasal 10 menyebutkan bahwa Satuan ruang geografis dapat ditetapkan sebagai Kawasan Cagar Budaya apabila:

1) Mengandung 2 (dua) Situs Cagar Budaya atau lebih yang letaknya berdekatan;

2) Berupa lansekap budaya hasil bentukan manusia berusia paling sedikit 50 (lima puluh) tahun;

3) Memiliki pola yang memperlihatkan fungsi ruang pada masa lalu berusia paling sedikit 50 (lima puluh) tahun;

4) Memperlihatkan pengaruh manusia masa lalu pada proses pemanfaatan ruang berskala luas;

5) Memperlihatkan bukti pembentukan lansekap budaya; dan

6) Memiliki lapisan tanah terbenam yang mengandung bukti kegiatan manusia atau endapan fosil.

Sebagian besar cagar budaya yang termasuk dalam Satuan Ruang Geografis Borobudur merupakan peninggalan kebudayaan Masa Hindu-Buddha di Indonesia, khususnya pada masa Kerajaan Mataram Kuno yang berlangsung dari abad VIII-X. Tinggalan arkeologis yang ada dalam satuan ruang geografis ini meliputi benda cagar budaya, struktur candi, bangunan candi, bangunan kolonial, lokasi atau situs cagar budaya. Kondisi yang dapat mengancam kelestarian cagar budaya tersebut, antara lain:

1) Perubahan tata guna lahan, yaitu dari sawah atau tanah produktif menjadi daerah pemukiman. Hal ini merupakan ancaman bagi ekosistem alami;

2) Pertumbuhan bangunan, dikarenakan beralihnya mata pencaharian penduduk dari pertanian ke sektor baran dan/atau jasa. Hal ini berpengaruh terhadap kuantitas bangunan yang dapat mengancam keberadaan zonasi yang mestinya untuk pelestarian; 
3) Banyaknya menara Base Transceiver Station (BTS). Tower tersebut dapat merusak integritas visual lansekap satuan ruang geografis Borobudur. Hal ini diperparah dengan adanya 17 menara BTS yang berada di zona III, IV,dan V, dan/atau

4) Pertumbuhan wisatawan. Jumlah rata-rata kunjungan wisatawan per tahun antara 3.000.000 sampai dengan 4.000.000 orang. Hal ini menurunkan tingkat keterpeliharaan Candi Borobudur.

Berdasarkan pertimbangan tersebut, maka pelestarian, pengembangan dan pemanfaatannya harus sesuai dengan ketentuan perundang-undangan yang berlaku.

Candi Ngawen merupakan salah satu Situs Cagar Budaya yang berada di dalam Satuan Ruang Geografis Borobudur. Berikut situs dan lokasi cagar budaya yang berada dalam Satuan Ruang Geografis Borobudur:

1) Situs Candi Borobudur

2) Situs Candi Mendut

3) Situs Candi Pawon

4) Situs Candi Ngawen

5) Lokasi Yoni di Brongsongan

6) Lokasi Candi Dipan

7) Lokasi Candi Bowongan

8) Lokasi Candi Samberan

9) Lokasi Yoni di Plandi

10)Lokasi Makam Belanda (Kerkhoff) Bojong di Mendut.

Sebelum Candi ditetapkan dalam Kawasan Cagar Budaya Nasional, Candi Ngawen masuk dalam rencana penataan pola ruang Kab. Magelang. Kawasan Cagar Budaya termasuk dalam rencana pola ruang wilayah karena untuk melindungi kekayaan budaya bangsa berupa peninggalan-peninggalan sejarah, bangunan arkeologi dan monument nasional, dan keragaman bentuk geologi, yang berguna untuk pengembangan ilmu pengetahuan dari ancaman kepunahan yang disebabkan oleh kegiatan alam maupun manusia. Hal tersebut tertuang dalam Peraturan Daerah Kabupaten Magelang Nomor 5 Tahun 2011 tentang Rencana Tata Ruang Wilayah Kabupaten Magelang Tahun 2010 2030. Diatur dalam RT/RW untuk menyikapi kondisi terkini dan antisipatif terhadap perkembangan di masa yang akan datang.

\section{PENUTUP}

Candi Ngawen merupakan candi yang cukup ideal dari sisi keletakkannya dengan didukung karakteristik lingkungan alamnya yang berupa gunung dan bukit, aliran sungai dan sumber mata air, persawahan dengan sistem irigasi yang berkesinambungan. Candi Ngawen dan lanskap yang ada disekitarnya merupakan suatu kesatuan yang tidak dapat dipisahkan dan saling mendukung. Lanskap yang didominasi oleh lahan pertanian di sekitar Candi Ngawen dapat menunjukkan hubungan antara manusia dengan lingkungan sekitarnya. Hingga saat ini lanskap Candi Ngawen tersebut masih terjaga. Kondisi tersebut dapat memberikan dukungan dalam upaya konservasi Kawasan Borobudur yang semakin ke depan terancam perkembangan jaman dan kebutuhan akan ruang. Upaya konservasi Kawasan Borobudur juga perlu mendapatkan dukungan dari berbagai pihak terkait, dalam hal melaksanakan berbagai perangkat aturan tentang keruangan dan pelestarian cagar budaya yang telah ditetapkan. 


\section{DAFTAR PUSTAKA}

Ahimsa-Putra, Heddy Shri. 2007. Pemberdayaan Masyarakat Dan Pelestarian Kawasan (Sebuah Sketsa Pemikiran). Disampaikan dalam Bimbingan Teknis Pengelolaan Situs Warisan Dunia, Borobudur 3 - 7 September 2007.

Ambarawati, Dwi Retno Sri. 2009. Kontinuitas Dan Perubahan Vastusatra Pada Bangunan Joglo Yogyakarta. Yogyakarta: Institut Seni Indonesia Yogyakarta.

Ardiyansyah, Panggah. 2019. "Analisis Nilai Penting Situs-Situs di Kawasan Cagar Budaya Borobudur". Borobudur Vol. 13 Nomor 1 Juni 2019 Hal 55-82.

Aryanto, Rudy, So, Gautama Idris. 2012. "Perencanaan Manajemen Lanskap Zonasi Destinasi Wisata Budaya Kota Tua Jakarta”. Binus Business Review Vol. 3 No. 2 November 2012: 973-982.

Boner, Alice dan Sarma, Sadasiva Rath. 1966. Translator Silpaprakasa, Medieval Orissan Sanskrit Text on Temple Architecture. Leiden: E. J. Brill.

Brown, Steven. 2007. Landscaping Heritage: Toward an Operational Culture Landscape Approach for Protected Areas in New South Wales. Australasian Historical Archaeology, Vol. 25 (2007), pp. 33 - 42.

Dananjaya, Putu. 2012. Model Pemanfaatan Sumberdaya Arkeologi Sebagai Objek Daya Tarik Wisata Studi Kasus Candi Sukuh. Tesis. UGM: Fakultas Ilmu Budaya.

Degroot, Veronigue Myriam Yvonne. 2009. Candi, Space and Landscape: A Study on the Distribution, Orientation and Spatial Organization of Central.Javanese Temple Remains. Disertasi: Universitas Leiden.

Firdani, Prita. Tanpa tahun "Deskripsi Dasar Kabupaten Magelang”. https://www.academia.edu/8875346/Deskripsi_Dasar_Kabupaten_Magelang.

Hardiati, Endang Sri. 1998. Aspek Arsitektural Dan Aspek Simbolik Bangunan Candi. Seminar Sehari Candi Sebagai Warisan Seni \& Budaya Indonesia 15 Agustus 1998. Yogyakarta: UGM.

Harjono, Timbul. 1980. Kompleks Candi Ngawen. Paper Untuk Kuliah Kerja Jurusan Arkeologi. Yogyakarta: Universitas Gadjah Mada.

Hartatik. 2014. Pemberdayaan Masyarakat Dalam Pengelolaan Sumberdaya Arkeologi: Sebuah Retrospeksi. Makalah dipresentasikan dalam Diskusi Ilmiah Arkeologi Ikatan Arkeologi Indonesia Komda Kalimantan. Banjarbaru, Kalimantan Selatan Minggu 21 September 2014.

Istari, Rita T.M. 2012. "Penemuan Sebuah Candi Bata Di Daerah Pantura Jawa Tengah". Berkala Arkeologi Vol. 32 Edisi No. 1/Mei 2012.

Jokilehto, Jukka. 2006. "Consideration on Authencity and Integrity in World Heritage Context”. City \& Time 2 (1). http://www.ct.ceci-br.org 
Junawan, dkk. 2012. “Zonasi Candi Ngawen Kabupaten Magelang”. Laporan. Klaten: Balai Pelestarian Cagar Budaya Jawa Tengah.

Karlstrom, Anna. 2013. Local Heritage and the Problem with Conservation dalam Transcending the Culture - Nature Divide in Cultural Heritage: Views from the Asia - Pacific region. ANU Press. https://www.jstor.org/stable/j.ctt5hgz2n.14.

Moleong, Lexy J. 1996. Metodologi Penelitian Kualitatif. Bandung: PT. Remaja Rosdakarya.

Muhammad, Chafid Fandeli. 2009. Prinsip-Prinsip Dasar Mengkonservasi Lanskap. Gadjah Mada University Press. Yogyakarta.

Mundardjito. 2002. Pertimbangan Ekologi Penempatan Situs Masa Hindu-Buda Di Daerah Yogyakarta. Jakarta: Wedatama Widya Sastra dan Ecole Francaise d'Extreme-Orient.

Plachter, H., dan Rossler, M. 1995. Cultural Landscapes: Reconnecting Cultural and Nature dalam Cultural Landscapes of Universal Value. Gustav Fisher Verlag. New York.

Rahmi, Dwita Hadi, Sudibyakto, H.A, Sutikno, H, Adhisakti, Laretna T. 2012. "Pusaka Saujana Borobudur: Perubahan dan Kontinuitasnya”. Jurnal Manusia dan Lingkungan Vol. 19 No. 1 Maret 2012 Hal: 85 - 94.

Rahmi, Dwita Hadi. 2012. Pusaka Saujana Borobudur Studi Hubungan Antara Bentanglahan dan Budaya Masyarakat. Ringkasan Disertasi. Yogyakarta: Sekolah Pascasarjana UGM.

Setyawati, Eva. 2016. Studi Amblesan Daerah Rawan Gerakan Tanah Di Desa Ngawen Muntilan Magelang Menggunakan Metode Geolistrik. Skripsi. Semarang: Jurusan Fisika. Fakultas Matematika dan Ilmu Pengetahuan Alam. Universitas Negeri Semarang.

Soekmono. 1974. Candi, Fungsi dan Pengertiannya. Disertasi. Jakarta: UI.

Sukendar, Haris. 2000. Metode Penelitian Arkeologi. Jakarta: Departemen Pendidikan Nasional Pusat Penelitian Arkeologi Nasional.

Stovel, Herb. 2007. "Effective Use of Authenticity and Integrity as World Heritage Qualifying Condition” City \& Time 2(3):3. http://www.ct.ceci-br.org

Tanudirdjo, Daud Aris. Tanpa tahun. Manajemen Sumberdaya Budaya. Jurusan Arkeologi. Fakultas Ilmu Budaya. Universitas Gadjah Mada.

Tanudirdjo, Daud Aris. Tanpa tahun. Melestarikan Warisan Budaya Kita. Jurusan Arkeologi. Fakultas Ilmu Budaya. Universitas Gadjah Mada.

Tim Peneliti. 2012. Penelitian Arsitektur Hindu - Buddha Di Candi Borobudur Dan Sekitarnya. Kabuoaten Magelang, Jawa Tengah (Tahap II). Jakarta: Puslitbang 
Arkenas, Badan Pengembangan Sumberdaya Kebudayaan dan Pariwisata, Kemenparekraf.

Wardiningsih, Sitti dkk. 2018. Nilai Penting Lanskap Budaya Minapadi Desa Bunisari. IKRAITH-HUMANIORA, Vol. 2 No. 2 Maret 2018. Jakarta: Institut Sians Dan Teknologi Nasional.

Yuwono, J. Susetyo Edy. 2007. Kontribusi Aplikasi Sistem Informasi Geografi (SIG) Dalam Berbagai Skala Kajian Arkeologi Lansekap. Berkala Arkeologi Tahun XXVII No. 2/November 2007.

Peraturan Daerah Kabupaten Magelang Nomor 5 Tahun 2011 tentang Rencana Tata Ruang Wilayah Kabupaten Magelang Tahun 2010 - 2030.

International Charter for the Concervation and Restoration of Monuments and Sites (The Venice Charter 1964).

Undang-Undang Republik Indonesia Nomor 11 Tahun 2010 tentang Cagar Budaya.

Profil Desa Ngawen Tahun 2017. Pemerintah Desa Ngawen. 